\title{
Community wide outbreak of hepatitis A linked to children in day care centres and with increased transmission in young adult men in Florida 1988-9
}

\author{
Jean-Claude A Desenclos, Laura MacLafferty
}

\begin{abstract}
Study Objective-To investigate a community wide outbreak of hepatitis A (HA). Design-Description of the outbreak, with a case-control study to assess transmission. Setting-A Florida county, USA, 1988-9. Subjects-A total of 311 cases of HA. Measurements and main results-A 13 month outbreak of HA is described. Most of the 311 cases $(95 \%)$ were residents of a large metropolitan area (attack rate per 10000 population $(A R)=3.7)$ and two smaller cities $(A R=61 \cdot 5$ and $A R=6 \cdot 4)$. The $A R s$ were greater for males than females and for residents aged 25-34 years $(9 \cdot 7)$ and $<5$ years $(8 \cdot 3)$. Altogether $37 \%$ of cases were linked to day care centres, independent of the city of residence. A household case-control study showed an increased risk of $\mathrm{HA}$ in households in which a child attended a day care centre $(p=0.02)$, and centres that could take more than 50 children had an increased risk of $H A$ introduction than smaller ones $(p=0 \cdot 05)$. Conclusions-Day care centres were an important source of $\mathrm{HA}$ in the community, and the need for timely surveillance and immunoglobin prophylaxis is emphasised. Homosexual transmission may have played an important role in this outbreak.
\end{abstract}

I Epidemiol Community Health 1993; 47: 269-273

Community wide epidemics of hepatitis A (HA), although less common than a few decades ago, still occur periodically in the United States. They are usually prolonged, account for large numbers of cases, and are difficult to control. ${ }^{1-3}$ In all these reported outbreaks, children who had not yet reached adolescence and women were at greater risk of infection. No clear source of infection was documented, however, and low socioeconomic status and educational attainment were the only common and recurrent risk factors reported. ${ }^{1-3}$ On the other hand, the spread of HA from young children to their carer has been well documented in day care centre outbreaks ${ }^{4-7}$ and this mode of transmission has been suggested as an important source of sporadic HA in towns. ${ }^{8}$ In addition, high rates of HA transmission and of outbreaks have been documented among homosexual men. ${ }^{8-10}$

We report a commmunity wide outbreak of HA in Orange County, Florida that lasted 13 months. Our investigation suggests that primary transmission to the community was from children who attended day care centres and documents an increased risk in young men, probably through homosexual transmission.

\section{Methods}

BACKGROUND

Orange County is located in central Florida and has a population of approximately 630000 residents (in 1989) of which $6.5 \%$ were $<5$ years old, and $80 \%$ lived in a large metropolitan area (city A). City B and city C, with populations of 13000 and 18000 residents respectively, are located 10 to 20 miles west of city A. Whites constitute $83 \%$ of the Orange County population and blacks $15 \%$; the proportion of Hispanic origin is $4.3 \%$. Most of the minority groups live in city $\mathrm{A}$. The socioeconomic statuses of those in city B and $\mathrm{C}$ tend to be lower than in A, and approximately 1000 of city B residents live in a mobile home community located near a sewage treatment plant.

\section{EPIDEMIOLOGICAL INVESTIGATION}

A case patient with HA was defined as any Orange County resident who, between 1 September 1988 and 31 October 1989, tested positive for HAV IgM antibody or was diagnosed as having HA by a physician. We defined a day care centre in which HA had been introduced as a centre with at least one attender with HA or with two or more cases of HA in two households with a child at the centre, and a day care centre outbreak as two or more cases among attenders or staff of the centre. ${ }^{6}$

Cases were identified from the reports of HA sent to the Orange County Public Health Unit by physicians, hospitals, medical laboratories, day care centres, schools, and private citizens. To encourage the reporting of cases of HA, the public health unit sent a letter to physicians and hospitals in March 1989. Reported cases (or their parents if $<18$ years) and/or their physicians were interviewed by telephone, by either of two trained Orange County Public Health Unit nurses. Information collected included name, address, age, gender, race, date of onset, hepatitis serology results, jaundice, risk factors for acquiring HA (attender or employee of a day care centre, household contact of a centre attender or employee, contact of a HA case within two to six weeks of onset, international travel, and commonsource outbreak), whether the case handled food, and the name of the day care centre attended if applicable. Information on sexual orientation was collected for HA patients initially reported as hepatitis and not yet confirmed as hepatitis A, B, or non-A, non-B. Data collection and control measures were reviewed periodically with the two nurses, and surveillance was increased in neighbouring counties to identify cases with a documented source of infection in Orange County.

To identify risk factors for the introduction of HA in a household, we conducted a matched 
We conducted a day care centre case-control study at the end of the outbreak to determine characteristics associated with HA introduction into a day care centre. Orange County day care centres with HA introduction during the epidemic were compared with a systematic random sample of HA-free centres selected from the Orange County licensure program 1989 day care centres list (4 control day care centres per case centre). Information available from the licensure program included the capacity of the facility, whether it was state funded, age range of children attending, whether the facility was part of a day care centre corporation, hours of operation per day. No information on "drop-in policy" (attendance on a day to day basis) was available from the centre licensure program.

Case-control data were analysed by calculating matched and unmatched odds ratios (OR) and $95 \%$ confidence intervals (CI) as appropriate. ${ }^{11} 12$ Household case-control data were further analysed by conditional multiple logistic regression to control for potential confounding factors. ${ }^{13}$ Statistical significance $(\mathrm{p} \leq 0.05)$ was assessed by the $\chi^{2}$ test with Yates's correction, Fisher's exact test, the McNemar $\chi^{2}$, the $\chi^{2}$ for trend as appropriate, ${ }^{11}$ and the likelihood ratio in conditional logistic regression. ${ }^{13}$

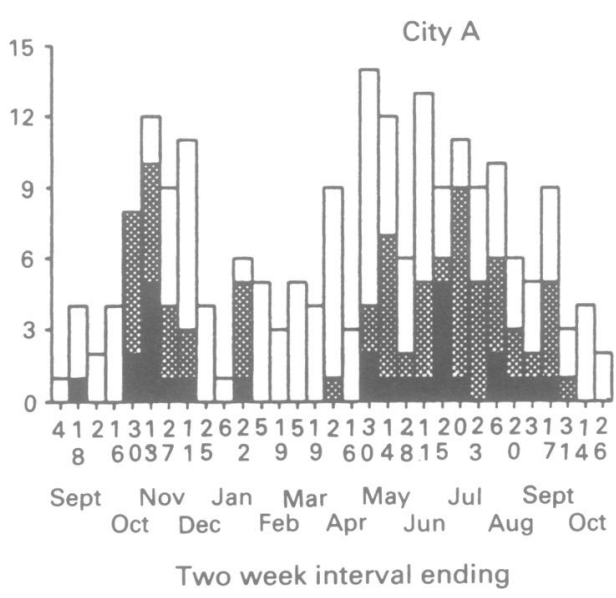

Figure 1 Cases of hepatitis $A$ by date of onset, city of residence and child day care centre association in Orange County, Florida between September 1988 and November 1989. Solid bars: day care centre attender or employee, hatched bars: household contact of day care centre attender; open bars: all other cases. Arrow indicates immunisation campaign by city $B$ public health clinic

Day care centres from which cases had been
ENVIRONMENTAL INVESTIGATION reported and the city B mobile home community and sewage treatment plant were inspected by an Orange County sanitary inspector. To assess a temporal relationship between episodes of sewage contaminated flooding and $\mathrm{HA}$ at the mobile home community, city B area rainfall levels were obtained from the local office of the National Oceanic and Atmospheric Administration.

\section{Results}

EPIDEMIOLOGICAL INVESTIGATION

From 1 September 1988 to 31 October 1989, 311 cases of HA were identified (attack rate per 10000 population $(A R)=4.9$ ), a more than tenfold increase compared with the previous 13 months. A total of 254 cases $(81 \cdot 7 \%)$ were positive for HAV IgM; $57(18.3 \%)$, were diagnosed by a physician, $41(13.2 \%)$ were admitted to hospital, and no HA death was reported.

HA cases occurred first in cities B and A in September 1988. The outbreak peaked in February 1989 and ended in July 1989 in cities B and C. In city A, cases occurred until October 1989 with peaks in October-November 1988 and MayJune 1989 (fig 1). Altogether $94 \%$ of all cases occurred in cities A-C (city A: 201 cases, $A R=3 \cdot 7$; city $B: 80$ cases, $A R=61.5$; and city $C: 12$ cases, $A R=6 \cdot 4$ ), and 242 households were affected with a mean of 1.3 cases per household (range: 1 to 8 ). Fifteen cases were residents of city $\mathrm{B}$ mobile home community ( $A R=150 / 10000)$. The ages of cases ranged from 3 months to 71 years, and the highest ARs were for those 25-34 years $(A R=9 \cdot 7)$ and $0-4$ years $(A R=8 \cdot 3$, fig 2$)$. The AR was greater for males $(5 \cdot 8)$ than for females $(4 \cdot 1) ; 285$ cases were white $(A R=5 \cdot 7)$, eight were black $(A R=0.9), 13$ were Hispanic $(A R=4 \cdot 8)$, and three were Asian (race unknown for two cases).
1989 or if any jaundice or flu-like syndrome with gastrointestinal symptoms was reported in any household member during the same period. 
Figure 2 Hepatitis $A$ attack rate in relation to age in Orange County, Florida between September 1988 and November 1989.

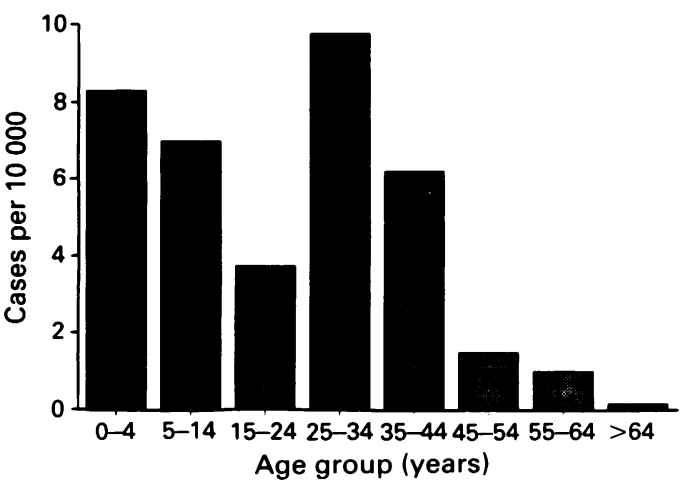

Of 302 cases in whom information was available, $111(36.8 \%)$ were related to day care centres (33 attenders, four employees, and 74 household contacts of a day care centre attender), and 83 who were not related to a day care centre had been in contact with a patient with HA two to six weeks before the onset of HA. Peaks in the total number of cases with HA were simultaneous with peaks of day care centre associated HA (fig 1). The proportions of day care centre related HA

Table I Cases of hepatitis $A$ in relation to day care centre association, age, and gender in Orange County, Florida between September 1988 and November 1989

\begin{tabular}{|c|c|c|c|c|c|c|c|c|c|c|}
\hline \multirow[b]{2}{*}{ Age (y) } & \multicolumn{3}{|c|}{ Male } & \multicolumn{4}{|c|}{ Female } & \multicolumn{3}{|c|}{ Total } \\
\hline & No & Total & $(\%)$ & $\overline{N o}$ & Total & (\%) & $p$ & No & Total & (\%) \\
\hline $0-4$ & 11 & 15 & $(73 \cdot 3)$ & 16 & 19 & $(84 \cdot 2)$ & NS & 27 & 34 & $79 \cdot 4$ \\
\hline $5-14$ & 7 & 37 & $(18.9)$ & 9 & 28 & $(32 \cdot 1)$ & NS & 16 & 65 & $24 \cdot 6$ \\
\hline $15-24$ & 3 & 27 & $(11 \cdot 1)$ & 12 & 21 & $(57 \cdot 1)$ & $\star$ & 15 & 48 & $31 \cdot 3$ \\
\hline $25-34$ & 15 & 62 & $(24 \cdot 2)$ & 19 & 33 & $(57.6)$ & $\star$ & 34 & 95 & 35.8 \\
\hline $35-44$ & 6 & 27 & $(22 \cdot 2)$ & 8 & 17 & $(47 \cdot 1)$ & NS & 14 & 44 & $31 \cdot 8$ \\
\hline $45-54$ & 0 & 3 & $(0.0)$ & 2 & 7 & $(28 \cdot 6)$ & NS & 2 & 10 & 10.0 \\
\hline$>54$ & 1 & 3 & $(33 \cdot 3)$ & 1 & 2 & $(50.0)$ & NS & 2 & 5 & 40.0 \\
\hline Total & 43 & 174 & $(24 \cdot 7)$ & 67 & 127 & $(52 \cdot 8)$ & $\star \star$ & 110 & 301 & $36 \cdot 5$ \\
\hline
\end{tabular}

Information missing for age and/or day care centre for 10 cases.

NS $p>0.05,{ }^{\star} p<0.01,{ }^{\star \star} p<0.001\left(\chi^{2}\right.$ with Yates's correction or Fisher's exact test as appropriate)

Table II Cases of hepatitis $A$ with and without risk factors for acquiring hepatitis $A$ by characteristics in Orange County, Florida between September 1988 and November 1989

\begin{tabular}{|c|c|c|c|c|c|c|c|}
\hline \multirow[b]{2}{*}{ Characteristics } & \multicolumn{2}{|c|}{$\begin{array}{l}\text { No risk factors* } \\
(n=93) \dagger\end{array}$} & \multicolumn{2}{|c|}{$\begin{array}{l}\text { One or more } \\
\text { risk factors } \\
(n=200) t\end{array}$} & \multirow{2}{*}{$\begin{array}{l}\text { Odds } \\
\text { ratio }\end{array}$} & \multirow[b]{2}{*}{$95 \% C I$} & \multirow[b]{2}{*}{$p$} \\
\hline & No & $(\%)$ & No & (\%) & & & \\
\hline $\begin{array}{l}\text { Male gender } \\
\text { Age } 18-40 \text { years } \\
\text { White } \\
\text { City A } \\
\text { Male ages } 18-40 \text { y } \\
\text { Homo/bisexual } \neq\end{array}$ & $\begin{array}{l}69 \\
66 \\
83 \\
62 \\
54 \\
26\end{array}$ & $\begin{array}{l}(74 \cdot 2) \\
(71 \cdot 0) \\
(89 \cdot 2) \\
(66 \cdot 7) \\
(58 \cdot 1) \\
(65 \cdot 0)\end{array}$ & $\begin{array}{r}98 \\
103 \\
185 \\
121 \\
49 \\
5\end{array}$ & $\begin{array}{l}(49 \cdot 0) \\
(51 \cdot 5) \\
(92 \cdot 5) \\
(60 \cdot 5) \\
(24 \cdot 5) \\
(27 \cdot 8)\end{array}$ & $\begin{array}{l}3 \cdot 0 \\
2 \cdot 3 \\
0 \cdot 7 \\
1 \cdot 3 \\
4 \cdot 3 \\
4 \cdot 8\end{array}$ & $\begin{array}{l}1 \cdot 7,5 \cdot 3 \\
1 \cdot 3,4 \cdot 0 \\
0 \cdot 3,1 \cdot 7 \\
0 \cdot 8,2 \cdot 3 \\
2 \cdot 4,7 \cdot 5 \\
1 \cdot 3,20 \cdot 5\end{array}$ & $\begin{array}{c}<0.001 \\
0.003 \\
0.5 \\
0.4 \\
<0.001 \\
0.02\end{array}$ \\
\hline
\end{tabular}

*Attender or employee of a day care centre, household contact of a day care centre attender or employee, contact of a hepatitis A case within two to six weeks of onset, international travel, and common-source outbreak

†Data on hepatitis A risk factors missing for 18 cases

$\ddagger$ Information available on 18 males with, and 40 males without risk factors of transmitting hepatitis $\mathrm{A}$

Table III Case and control households in relation to household characteristics during a hepatitis $A$ outbreak in Orange County, Florida during April 1989

\begin{tabular}{|c|c|c|c|c|c|c|c|}
\hline \multirow[b]{2}{*}{ Characteristics } & \multicolumn{2}{|c|}{$\begin{array}{l}\text { Case households } \\
(n=29)\end{array}$} & \multicolumn{2}{|c|}{$\begin{array}{l}\text { Control } \\
\text { households } \\
(n=29)\end{array}$} & \multirow{2}{*}{$\begin{array}{l}\text { Odds } \\
\text { ratio.* }\end{array}$} & \multirow[b]{2}{*}{$95 \% C I^{*}$} & \multirow[b]{2}{*}{$p$ value } \\
\hline & No & $(\%)$ & No & $(\%)$ & & & \\
\hline \multirow{7}{*}{$\begin{array}{l}\text { Child }<3 \text { y } \\
\text { Child in nappies } \\
\text { Child in day care } \\
\text { centre† } \\
\text { Contacts with a case } \\
\text { within } 2-6 \text { wks } \\
\text { Owned home } \\
\text { Low income } \\
\text { (<\$10 000/year) } \\
\text { Low education\| } \\
\text { ( } \leq \text { High school) }\end{array}$} & 13 & $(44 \cdot 8)$ & 8 & $(27 \cdot 6)$ & $3 \cdot 5$ & & 0.2 \\
\hline & 12 & $(41 \cdot 4)$ & 4 & $(13 \cdot 8)$ & $9 \cdot 0$ & $1 \cdot 1,71 \cdot 0$ & 0.03 \\
\hline & 8 & $(27 \cdot 6)$ & 1 & $(3 \cdot 4)$ & $t$ & $1.9+$ & 0.02 \\
\hline & 13 & $(44 \cdot 8)$ & 4 & $(13 \cdot 8)$ & $5 \cdot 5$ & $1 \cdot 2,24 \cdot 8$ & 0.03 \\
\hline & 19 & $(67 \cdot 8)$ & 23 & $(79 \cdot 3)$ & $0 \cdot 3$ & $0 \cdot 1,2 \cdot 0$ & 0.5 \\
\hline & 11 & $(47 \cdot 8)$ & 10 & $(37 \cdot 0)$ & $1 \cdot 5$ & $0 \cdot 4,5 \cdot 3$ & $0 \cdot 8$ \\
\hline & 17 & $(68 \cdot 0)$ & 12 & $(41 \cdot 4)$ & $8 \cdot 0$ & $1 \cdot 0,64 \cdot 0$ & $0 \cdot 05$ \\
\hline
\end{tabular}

${ }^{\star}$ Matched analysis based on Mantel Haenszel method, ${ }^{11}$ unless otherwise specified

tApproximate lower value of the $95 \%$ CI based on the binomial probability distribution ${ }^{12}$

f Anformation obtained in 28 case households and 29 control households

\|Information obtained in 25 case households and 29 control households were greater in the age groups $<5$ years and $25-34$ years and in females than males of all age groups (table I). Ninety eight per cent of day care centre related cases were white $(109 / 111)$ compared with $88 \%(169 / 193)$ for the other cases $(p=0.003$, information missing for seven cases). Of the 238 households with more than one case of HA, 80 (34\%) had a child in a day care centre, independent of the city of residence (city $\mathrm{A} 36.7 \%$, cities $B$ and $C 26 \cdot 6 \%$, other cities $25 \%, p=0 \cdot 3$ ). Of 12 day care centres associated with one or more case of HA, 10 had HA introduction and eight a day care centre outbreak (one in city $B$ and seven in city A). Day care centre outbreaks ranged from two to 25 in number of cases (median=12) and from two to 26 weeks in duration (median 13 weeks). Twenty six per cent (10/39) of HA cases in a neighbouring county in 1989 were linked to day care centres implicated in the Orange County epidemic.

Ninety three of the 293 cases for whom information was available had none of the common risk factors for acquiring HA (that is none of the following: attender or employee of a day care centre, household contact of a day care centre attender or employee, contact of a HA case within two to six weeks of onset, international travel, and common-source outbreak). When compared with cases with these risk factors, cases without HA risk factors were more likely to be male, to be 18 to 40 years old, and to be reported as homosexual or bisexual (table II).

Forty one case households were eligible for the case-control study, and 30 (73\%) were reached by telephone and agreed to participate in the study. Appropriate matched control households were interviewed for 29 of the case households. Case and control households did not differ significantly in relation to the number of occupants per bedroom or bathroom or by income level. The risk (OR) of HA introduction was increased for households with children who were in nappies, with children attending a day care centre, with no education beyond high school, and when contacts with HA cases(s) had occurred (table III). In conditional multiple logistic regression, the three following variables were the only significant risk factors: child cared for in a day care centre (likelihood ratio $=12 \cdot 2, \mathrm{p}<0.01$ ), low educational status (likelihood ratio $=6 \cdot 5, \mathrm{p}<0.01$ ), and contact with HA case(s) outside the household (likelihood ratio $=4, \mathrm{p}=0.05$ ).

Case day care centres were more likely to be licensed for a capacity of more than 50 (table IV). The risk of HA introduction tended to increase with the capacity of the day care centre $(\chi 2$ for trend $=2 \cdot 7, \mathrm{p}=0 \cdot 1$ ).

Parents with children attending a day care centre with an HA outbreak were notified by mail by the county public health unit and immunoglobulin prophylaxis was recommended for all household members. The time interval between the onset of the first day care centre case of HA and the parent receiving mail advice ranged from two to seven weeks. Immunoglobulin was delivered through family practitioners and was also recommended for household contacts of any case within two weeks of onset. The city B public clinic (that served cities $\mathbf{B}$ and $\mathbf{C}$ ) undertook a more active approach, however, and provided free 
Table IV Day care centres (DCCs) with (cases) and without (controls) hepatitis $A$ introduction in relation to centre characteristics during a hepatitis $A$ outbreak in Orange County, Florida in November 1989

\begin{tabular}{|c|c|c|c|c|c|c|c|}
\hline \multirow{2}{*}{$\begin{array}{l}\text { DCC } \\
\text { Characteristics }\end{array}$} & \multicolumn{2}{|c|}{$\begin{array}{l}\text { Case DCCs } \\
(n=10)\end{array}$} & \multicolumn{2}{|c|}{$\begin{array}{l}\text { Control } \\
D C C s \\
(n=40)\end{array}$} & \multirow{2}{*}{$\begin{array}{l}\text { Odds } \\
\text { ratio }\end{array}$} & \multirow[b]{2}{*}{$95 \% C I$} & \multirow[b]{2}{*}{$p$ value } \\
\hline & No & $(\%)$ & No & $(\%)$ & & & \\
\hline In city $A$ & 6 & $60 \cdot 0$ & 31 & $77 \cdot 5$ & 0.4 & $0 \cdot 1,2 \cdot 6$ & 0.4 \\
\hline Funded & 2 & $20 \cdot 0$ & 11 & $27 \cdot 5$ & 0.7 & $0 \cdot 1,4 \cdot 1$ & 1.0 \\
\hline Corporation & 5 & $50 \cdot 0$ & 11 & $27 \cdot 5$ & $2 \cdot 6$ & $0.5,13.8$ & $0 \cdot 3$ \\
\hline Capacity $>50$ & 10 & $100 \cdot 0$ & 27 & $67 \cdot 5$ & $\star$ & $0.9, \star$ & 0.05 \\
\hline Attenders aged $<1 \mathrm{y}$ & 8 & $80 \cdot 0$ & 24 & $60 \cdot 0$ & $2 \cdot 7$ & $0 \cdot 4,28 \cdot 5$ & $0 \cdot 3$ \\
\hline After hours operation & 10 & $100 \cdot 0$ & 29 & $72 \cdot 5$ & $\star$ & $0 \cdot 7, \star$ & 0.09 \\
\hline
\end{tabular}

immunoglobulin to attenders and staff of day care centres and contacts of HA cases. From January to April more than 700 immunoglobulin injections were provided by the city B public clinic. Of those, $80 \%$ were given during the second and third week of February 1989, approximately six weeks after the onset of the first case in a day care centre. A sharp decrease in HA cases occurred thereafter (fig 1).

\section{ENVIRONMENTAL INVESTIGATION}

In day care centres in which cases occurred, sanitary inspectiion did not note any major mistakes in nappy changing, hand washing, food handling, or storage and refrigeration procedures The sewage treatment plant in city B had been operating since 1984 and there had been frequent deficiencies such as vegetable overgrowth, pond overflow, and illegal discharge of sewage water that directly affected the mobile home community. When the plant was abandoned in February 1989, several episodes of sewage contaminated flooding occurred after heavy rains Mobile home residents reported that many children had played in the "sewage contaminated" water but HA cases did not tend to cluster within one incubation period of heavy rains. All but one of the HA patients from the city $B$ mobile home community had close contact with other mobile home community case(s).

\section{Discussion}

This community wide outbreak of HA lasted more than one year and accounted for more than $25 \%$ of all the HA cases in Florida for the same time period (Florida Department of Health and Rehabilitative Services. Unpublished data, 1990). Although all patients with HA recovered, the public health consequences of the outbreak were substantial in terms of morbidity and direct and indirect costs. ${ }^{1}$ In cities B and C, the household case-control study suggested that having children in day care centres was an important risk factor for the introduction of HA in households. Although no case-control study was undertaken in city $A$, we believe that day care centres also played a major role there since the proportion of case households with toddlers attending day care centres tended to be greater in city A than in cities B and C. Person to person transmission of HA between toddlers in day care centres and their carers at home has been well documented in the past. ${ }^{4-8}$

The day care centre case-control study indicated that a centre capacity greater than 50 children was a risk factor for HA introduction. Previous studies have reported a similar finding and also an increased risk of HA introduction in centres that care for infants, those opened 15 or more hours/day, and centres operating for profit. ${ }^{6}$ Although the limited sample size of our study does not allow any conclusion, case day care centres also tended to enroll very young children, to operate after hours, and to be part of a day care centre corporation more frequently than control centres. We did not study "drop-in" day care centre policy, however, another risk factor in previous outbreaks. ${ }^{6}$ The increased risk of HA associated with large capacity centres suggests that they should be targeted for surveillance and control activities during any community outbreaks of HA.

Although toddlers in nappies in day care centres were a likely primary source of infection in this community wide outbreak, the reasons for a more than tenfold $A R$ variation between cities $A$ and $B+C$ are unclear. The extremely high $A R$ in the city B mobile home community suggested a link between HA and city B's malfunctioning sewage treatment plant. No further evidence of such an association could be found, however, and a previous study showed no increased risk of $\mathrm{HA}$ after drinking sewage contaminated water. ${ }^{14}$ As in previous community wide outbreaks, a lower level of education and hygiene could also have contributed to the difference between cities. ${ }^{1-3}$ This is suggested by the greater risk of HA introduction in households with lower educational attainment and socioeconomic status in cities B and C. The racial differences in ARs and in the proportion of day care centre related cases may suggest differences in the level of immunity in relation to racial and ethnic groups, particularly for adults. Indeed, population based serological studies have shown that the prevalence of immunity to HAV in adults is greater for those of lower socioeconomic status (as is often the case for Blacks) and those born and raised in less developed countries (for example, Hispanic people)..$^{15}$ We do not however, have immunity figures for HAV in relation to age, race, and ethnicity in Orange County or in Florida. In addition, attenders of the day care centres affected in this outbreak were predominantly white.

This outbreak, however, differs from other community wide outbreaks reported in the past. Attack rates were greater for males, for young adults, and for children $<5$ years, but not for females and children 5 to 14 years. ${ }^{1-3}$ The age pattern is probably related to HA transmission in day care centres, and from infected centre attenders to their parents at home. The greater risk for males than for females was not expected because young females would be more exposed to children infected in day care centres and because of the stronger association between women and day care centres (table I).

The preponderance of HA in men is probably related to homosexual transmission in young adult men. Data to support this hypothesis come from comparing cases with none of the common HA risk factors with those with these risk factors in relation to male gender, age, and homosexuality or bisexuality, or both. Although information on sexual orientation was available for a subset of cases only (a potential source of bias) our interpretation is consistent with previous reports of high rates of HA transmission in homosexual men. ${ }^{910}$ This probable association between HA and homo- 
sexuality in 1989 in Florida coincides with a series of reports of outbreaks of HA among homosexuals in the USA, Canada, and Australia in 1991. ${ }^{17} \mathrm{~A}$ high rate of hepatitis $A$ in homosexual men may reflect an increase in sexual practices that promote faecal contamination (for example, oral-anal contact).

Outbreaks of HA in day care centres accounted for a third of all cases, but contributed to many more if one considers tertiary transmission. ${ }^{5}{ }^{8}$ In the United States the incidence of HA increased substantially in 1989 compared with $1988 ;^{18}$ in Florida a similar trend was observed, and in day care centres outbreaks were more frequent in other Florida counties in 1989 than in 1988 (Florida Department of Health, unpublished data, 1990).

Previous studies have shown that timely administration of immunoglobulin during HA outbreaks in day care centres can limit the outbreak size and reduce transmission into the community. ${ }^{7}$ Although Orange County HA control measures followed well established recommendations, ${ }^{19}$ they were not implemented very quickly, and some outbreaks in centres lasted more than four months. In cities B and C, where immunoglobulin was used more aggressively, the incidence of HA decreased after maximal immunisation efforts suggesting an impact on HA transmission. ${ }^{3} 7$ City A experienced a longer outbreak, because day care centres were affected successively and possibly because of the policy based solely on immunisation by private health providers.

This investigation shows that day care centres are still an important source of community HA and underlines the need for increased HA surveillance in these centres and implementation of immunisation recommendations at the earliest signs of transmission within a particular community. It is also suggested from this investigation that homosexual transmission could play an important role in community wide outbreaks of HA.
We thank Janette Wahler, RN, Nilda Garcia, RN and Bill Toth, MPH, for their help in data collecting, and James $\mathrm{T}$ Wassell for statistical assistance.

1 Shaw FEJ, Sudman JH, Smith SM et al. A community-wide epidemic of hepatitis A in Ohio. Am 7 Epidemiol 1986; 123. epidemic

2 Mosley WH, Speers JF, Chin TDY. Epidemiologic studies of a large outbreak of infectious hepatitis. Am $\mathcal{F}$ Public Health 1963; 53: 1603-17

3 Pavia AT, Nielsen L, Armington L, Thurman DJ, Tierney E, Nichols GR. A community-wide outbreak of hepatitis A in a religious community: impact of mass administration of immune globulin. Am f Epidemiol 1990; 131: 1085-93.

4 Storch G, McFarland LM, Kelso K, Heilman CJ, Caraway CT. Viral hepatitis associated with day care centres. $¥ A M A$ 1979; 242: 1514-8.

5 Hadler SC, Webster HM, Erben J, Swanson JE, Maynard JE. Hepatitis $\mathrm{A}$ in a day care centers, a community assessment. $N$ Engl F Med 1980; 302: 1222-7.

6 Hadler SC, Erben JE, Francis DP, Webster HM, Maynard JE. Risk factors for hepatitis A in day-care centers. $\mathcal{J}$ Infect Dis 1982; 145: 255-61.

7 Hadler SC, Erben JJ, Matthews D, Starko K, Francis DP, Maynard JE. Effect of immunogivbulin on hepatitis A in day Maynard JE. Effect of immunogisbulin

8 Lemon SM. Type A viral hepatitis, new developments in an Lemon SM. Type A viral hepatitis, new developm
old disease. N Engl f Med 1985; 313: 1058-67.

9 Corey L, Holmes KK. Sexual transmission of hepatitis A in homosexual men, incidence and mechanism. $N$ Engl f Med 1980; 302: 435-8.

10 Christenson B, Brostrom C, Bottiger $M$ et al. An epidemic outbreak of hepatitis A among homosexual men in Stockholm: hepatitis A, a special hazard for the male homosexual subpopulation in Sweden. Am $\mathcal{f}$ Epidemiol 1982; 116: 599-606.

11 Dean AD, Dean JA, Burton JH, Dicker RC. Epi Info, Version: a word processing, database, and statistical program for epidemiology on micro-computers. Centers for Diseas Control, Atlanta, Georgia, U.S.A., 1990.

12 Fleiss JL. Statistical methods for rates and proportions. New York: John Wiley \& Sons, 1981.

13 Schlesselman JJ. Case-control studies, design, conduct, analysis. New York: Oxford University Press, 1982.

14 Rosenberg ML, Koplan JP, Pollard RA. The risk of acquiring hepatitis fromm sewage-contaminated water. $\mathrm{Am} \mathscr{f}$ Epidemiol 1980; 112: 17-22.

15 Szmuness W, Dienstag JL, Purcell RH et al. Distribution of antibody to hepatitis A antigen in urban adult population. $N$ Engl f Med 1976; 295: 755-9.

16 Lemon SM. Type A viral hepatitis: new developments in an old disease. N Engl F Med 1985; 313: 1059-67.

17 Centers for Disease Control. Hepatitis A among homosexua men-United States, Canada, and Australia. MMWR 1992; 41: 155-64.

18 Centers for Disease Control. Foodborne hepatitis AAlaska, Florida, North Carolina, Washington. MMWR 1990; 39: 228-32.

19 Report of the Committee on Infectious Diseases (Red Book). Elk Grove Village, IL: American Academy of Pediatrics, 1988 . 